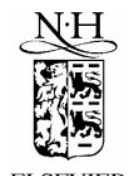

International Journal of Industrial Organization 19 (2001) 567-588

\title{
To invest or screen efficiently: a potential conflict in relationships governed by incomplete contracts
}

\author{
Mehmet Bac* \\ Bilkent University, Department of Economics, Bilkent, Ankara, 06533 Turkey
}

Received 1 June 1997; received in revised form 1 June 1998; accepted 1 June 1999

\begin{abstract}
We consider a dynamic trade relationship where quality is not contractible and potential sellers retain quality-relevant private information. We show that the presence of an investment technology to improve the incumbent seller's innate quality may impair the efficiency of the screening process. If the conflict is effective, the buyer has to induce an inefficient screening process or reduce the productivity of the investment technology. This conflict suggests that the hold-up problem may be more severe than predicted by models of incomplete contracts that assume complete information. (C) 2001 Elsevier Science B.V. All rights reserved.
\end{abstract}

Keywords: Incomplete contracts; Screening; Relationship-specific investments; Bayesian equilibrium JEL classification: L14; J41

\section{Introduction}

Virtually all real-life contracts are incomplete. Payoff-relevant aspects of exchange such as 'quality' can rarely be fully specified and made enforceable by courts. The consequence of contract incompleteness is opportunistic behavior, as for instance the sellers will have an incentive to withhold effort and expenditures,

\footnotetext{
*Tel.: +90-312-290-2068; fax: +90-312-266-5140.

E-mail address: bac@bilkent.edu.tr (M. Bac).
} 
and manipulate the noncontractible aspect to their private benefit. Imperfect information about potential trading partners' types exacerbates the problem. The missing, private information, such as potential sellers' 'innate abilities' to provide a better (noncontractible) quality, may be quite relevant for the buyer. Another important feature of dynamic contractual relationships is that these abilities or the potential to provide a better quality may improve over time through bilateral investments which, often, are also noncontractible. Consider, for example, a manufacturer who needs to subcontract an item whose quality is noncontractible and potential subcontractors retain private information about their abilities and knowhow, which can be improved through bilateral investments. In such trade relationships, the objectives of the buyer (manufacturer) are to screen out sellers (subcontractors) of 'bad' innate quality as early as possible, build up a relationship with a 'good' seller and improve the quality of the customized item through bilateral investments.

This paper studies the interaction between these objectives in a dynamic game and identifies a new source of inefficiency, a potential conflict between the buyer's screening concerns and investment incentives. The game starts with the buyer's contract (price) offer to potential sellers who are privately informed about their innate qualities. Sellers make acceptance choices and the buyer chooses one among those who accept. During the contract, the incumbent seller decides on his temporary quality-improving effort and invests on his innate quality simultaneously with the buyer. If the contract is a short-term contract, the buyer decides on whether to extend the relationship and, in the affirmative, the parties negotiate the terms of the second (last) contract.

The main message of this paper is that in such bilateral trade relationships the presence of an investment technology to improve the incumbent seller's innate quality can impair the efficiency of the screening process.' Screening out 'bad' seller types efficiently by inducing the incumbent seller to exert effort and signal a 'good' type may stipulate a relatively high first-contract price. However, a 'bad' seller who foresees the buyer's equilibrium investment strategy may accept the contract and penetrate into the relationship, invest his part, improve his innate quality and lock the buyer in for the second contract. This potential penetration strategy upsets the screening equilibrium. The buyer should then either induce a nonscreening equilibrium (offer a contract accepted by all seller types) or an inefficient screening equilibrium where only the 'good' seller types accept but the incumbent seller exerts suboptimal effort. Alternatively, the buyer may replace the investment technology by a less productive one or make binding commitments

\footnotetext{
${ }^{1}$ An efficient screening process consists of an outcome in which only the 'good' seller types accept the initial contract and the incumbent seller exerts the effort level maximizing the joint surplus from temporary quality improvement, while type information is transmitted to the buyer. In Section 3 we characterize briefly the overall efficiency in this relationship.
} 
about the level of her post-contract investment. The conflict identified above should be at work in many real-life economic relationships governed by incomplete contracts, where initially information is asymmetric and the parties undertake bilateral investments to improve future gains from trade.

The analysis builds on an extensive literature where existing models focus on one or two of the three main features, noncontractibility, asymmetric information and relationship-specific investments. The present paper combines all three. A major finding in the field that emerged from Willamson's $(1975,1985)$ seminal work on problems of opportunism is known as the hold-up problem: Relationshipspecific investments will be suboptimal when contract incompleteness prevents the investing party from appropriating the full returns. ${ }^{3}$ Farrell and Shapiro (1989) and Bac (1993, 1997) have studied the question as to what incomplete contracting procedures provide protection against opportunism and adverse selection. The answer is that in the absence of external uncertainty short-term contracts that leave continuation open perform better than long-term contracts. Intuitively, leaving continuation open avoids post-contractual opportunistic behavior. When one party is locked-in and committed to trade at a given price, the other party will manipulate the noncontractible variables to his own private benefit, often at the expense of the committed party.

\footnotetext{
${ }^{2}$ The Oakland Cable TV franchising experience discussed at length by Williamson (1985) (pp. 352-364) provides a concrete example. Williamson mentions that noncontractibility of the quality of TV signals generated problems of opportunism and numerous customer complaints. Though the city of Oakland had monopoly power at the outset, its relationship with the service provider turned into a bilateral monopoly, and the shift in the bargaining power affected the negotiations over continuation terms. Heavy investments were needed on both sides (the city had to devote resources to enforce improvements in service quality, and the service provider had to build infrastructure). The presence of several potential service providers indicates that adverse selection concerns should also have played a role. The franchise was awarded to Focus Cable of Oakland, who accepted having to provide the service at a price much lower than its competitors. Our results suggest that this low price (which turned out to be introductory) is likely to have induced a screening equilibrium with a suboptimal qualityimproving effort by Focus.

${ }^{3}$ Crawford (1988) studies contracting procedures when parties undertake relationship-specific investments under complete information. Bilateral investments in our model are different in that they increase the buyer's willingness to pay. See Hart and Moore (1988) and Tirole (1986) for formal studies of the hold-up problem.

${ }^{4}$ Static models have shown that menus of contracts can mitigate asymmetric information and screening problems. In a class of models (Freixas et al., 1985; Laffont and Tirole, 1988) dynamics have a negative effect on intertemporal incentives. Holmstrom (1982) has shown that this 'ratchet effect' may be reversed under incomplete contracting procedures with career concerns. In this paper, as in Bac (1993, 1997), dynamics enhance effort incentives of the incumbent seller by providing a motive of signalling a high innate quality. A common feature of dynamic incomplete contracting models, including the present one, is that in equilibrium successful screening/signalling obtains only if the agent expects capturing a sufficient continuation surplus.

${ }^{5}$ This contrasts with the answer given under complete contracting. See, for instance the results of Fudenberg et al. (1990).
} 
Investments that generate a direct benefit to the investor's trading partner have received little attention in the literature. ${ }^{6}$ For example, R\&D investments that defence contractors undertake for the Department of Defence, and subcontractors' efforts to customize their components to the special needs of manufacturers have the effect of increasing the buyer's future benefits from trade. They are becoming increasingly common and important, especially with the growing emphasis on the buyer-supplier alliance in industrial purchasing. Recent models of dynamic incentive contracts focus on specific investments that do not exert direct benefits on the investor's trading partner. The efficiency results under ex post renegotiation by Chung (1991), Aghion et al. (1994), and Edlin and Reichelstein (1993) are restricted to this self-investment case.

The paper is organized as follows. The next section presents a two-period model of the buyer-seller relationship. The analysis in Section 3 characterizes equilibria. In Section 4 we specialize using a simple, proportional solution to the secondperiod bargaining problem. Section 5 concludes.

\section{The model}

We consider a two-period buyer-seller relationship, represented in Fig. 1. The buyer has a unit demand of a good or service in each period, some attributes of which (called quality and denoted $q$ ) are not contractible. It costs $c$ to supply one unit to the buyer. ${ }^{8}$ A large number of potential sellers retain private information about an important variable affecting quality, called innate quality and denoted $\theta$. We assume that $\theta$ can take either a high value $\theta_{\mathrm{H}}$ or a low value $\theta_{\mathrm{L}}$. The prior probability $\pi$ that a randomly selected seller is of type $\theta_{\mathrm{H}}$ is common knowledge. The sellers' outside option is normalized to zero.

\footnotetext{
${ }^{6}$ The labor context may be an exception. For a theory and the evidence on training general skills, see Acemoglu and Pischke (1996) and the references cited therein. Bac (forthcoming) modifies the present model and applies to the labor context by allowing for training and investments in general and specific skills under asymmetric information and special assumptions about the distribution of bargaining power at the contract renewal stage (for instance, attributing all the bargaining power to the employer when the worker undertakes general investments that improve his outside option). The analysis derives predictions on the factors shaping lifetime wage profiles, an issue which attracted considerable interest in the labor literature. The results suggest that the potential conflict identified in the present paper is robust to various contextual features of contractual relationships.

${ }^{7}$ The two-period assumption is chosen for simplicity. The model can be extended to a multi-period, or continuous-time, setting. The only impact of this extension will be to introduce a wider set of choices for contract durations (a single contract may then govern several periods, or the entire future). See Bac (1993) for a continuous-time model with adverse selection and noncontractibility of output.

${ }^{8}$ For instance, the standard version of the good or service, which is available in the market at the price $c$, may not satisfy the buyer's idiosyncratic needs so that she has to develop a bilateral relationship with a seller to get an improved quality.
} 


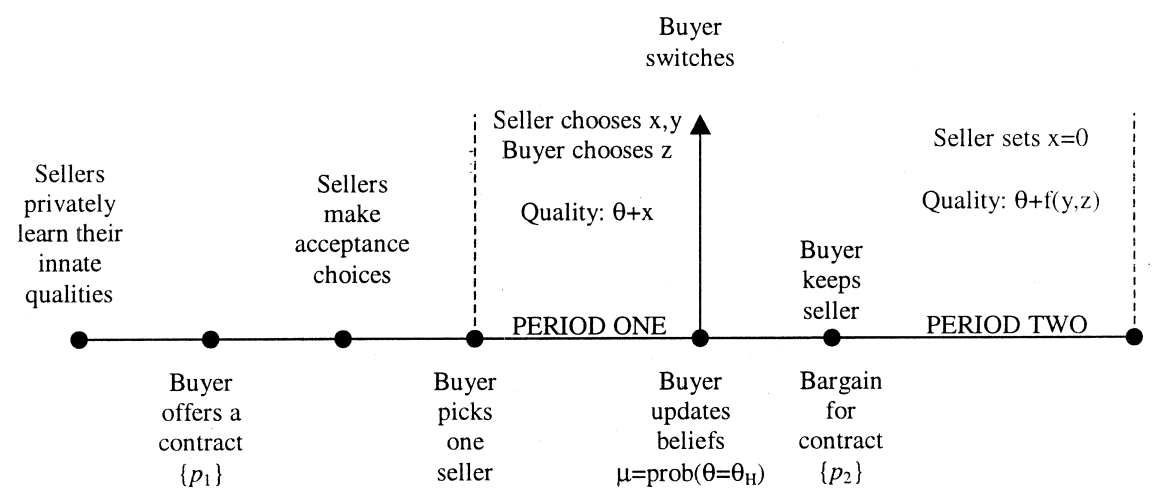

Fig. 1. The sequence of events in the buyer-seller relationship.

There are two ways in which quality can be improved. First, it can temporarily be improved through the seller's effort. Given the incumbent seller's innate quality $\theta$, the effort $x_{t}$ generates the quality $q=\theta+x_{t}$ in period $t$. The buyer does not observe effort, but observes delivered quality. Second, quality can be improved through bilateral investments in the innate quality of the incumbent seller. We assume that investment in quality (as quality itself) is noncontractible, entirely relationship-specific, but observable at the end of period one. 'The seller's and the buyer's first-period investments $y$ and $z$ generate an improvement in the nextperiod quality according to the function $f(y, z)$, which is increasing in its arguments and strictly concave. Investment decisions are simultaneous and possibly made under incomplete information as the buyer may not know the seller's type at the corresponding stage. The parties observe the investment decisions at the end of period one. Thus, if the relationship extends to the second period, it is common knowledge that the incumbent seller's innate quality will improve by $f(y, z)$.

The buyer cares about quality, the price she pays, and her investment decision. We measure units so that her per-period utility is simply $u_{\mathrm{B}}=q-p-z$. The seller who is on contract for the first period with the buyer receives the utility $u_{\mathrm{S}}=p-c-d(x)-y$, where $d(x)$ is the strictly convex and increasing effort disutility function.

A brief characterization of the conditions for overall efficiency in this twoperiod relationship will provide a reference point for the analysis in Section 3 and identify the potential sources of inefficiencies. In each period, the efficient

\footnotetext{
${ }^{9}$ This is also a simplifying assumption. We could have assumed that part of the investments made by the two parties are general and thus improve the seller's outside option. The only, quite predictable, impact of this assumption would be to improve the incumbent seller's bargaining power, which would be reflected in a higher second-period price.
} 
quality-improving effort of the incumbent seller maximizes the corresponding joint surplus $q-d(x)$, thus satisfies $1=\partial \phi(d) / \partial d$, where $\phi($.$) is the inverse of the$ effort-disutility function $d($.$) . Because quality is not contractible, in the second$ period the seller will withhold effort, thus quality will be just equal to the improved innate quality $\theta+f(y, z)$. However, signaling considerations in the first period may induce the incumbent seller to exert effort and temporarily improve quality. The efficient investment pair maximizes the joint surplus $f(y, z)-y-z$. This condition usually does not obtain in the equilibria of our game because investment decisions are noncooperative and noncontractible. The first-best contractual arrangement also involves full screening out of $\theta_{\mathrm{L}}$-sellers and continuation with a $\theta_{\mathrm{H}}$-seller. If all other variables could be set at their first-best levels (in other words, if quality and investment decisions were contractible), the prices $p_{1}$ and $p_{2}$ would be mere transfers and have no efficiency consequence, thus would be set to satisfy the participation constraint of $\theta_{\mathrm{H}}$-sellers.

In this relationship, the unit price, contract duration, and the fact that the buyer must be delivered one unit of the good or service in each period are the contractible variables. ${ }^{10}$ In terms of durations, there are two possibilities: A 'long-term' contract $\left\{p_{1}, p_{2}\right\}$ which specifies the prices for the two periods, and a 'short-term' contract $\left\{p_{1}\right\}$ that makes no reference to continuation and leaves open the second-period price. Besides determining how the expected surplus will be shared, the governing contract may perform several functions. Prices may serve the purpose of screening out a seller type or generating separation of types so that the buyer learns the incumbent seller's type at the end of period one. Applied to this setting, Farrell and Shapiro (1989) 'principle of negative protection' implies that long-term contracts are dominated by short-term contracts with continuation left open. A long-term contract $\left\{p_{1}, p_{2}\right\}$ where $p_{2}$ is already specified eliminates the link between the incumbent seller's incentives to invest on improving his innate quality and the second-period price. We shall accordingly confine the following analysis to short-term contracts. ${ }^{11}$

Under a short-term contract $\left\{p_{1}\right\}$, the buyer observes quality and investments, updates her beliefs $\mu\left(\theta_{\mathrm{H}} \mid q_{1}, y\right)=\operatorname{prob}\left(\theta=\theta_{\mathrm{H}}\right)$ given $q_{1}$ and $y$, then makes a continuation decision $b \in\{0,1\}$ as the first period expires. She either continues

\footnotetext{
${ }^{10}$ Quality and investments in quality are not contractible, but observable ex post to both parties. Note that noncontractibility precludes present and future prices that depend on present and future quality and investment.

${ }^{11}$ Long-term contracts generate a lower surplus for the buyer even in the absence of investment possibilities. Given noncontractibility of an important aspect of trade, commitments about future contractible variables (prices) invite opportunism because the trading partner (the seller) will manipulate the noncontractible variable (quality). as discussed in Bac (1993, 1997), long-term contracts involving such commitments thus provide a negative protection to the buyer, the party vulnerable to sellers' opportunistic behavior.
} 
with the incumbent seller $(b=1)$ or terminates the relationship and contracts with an outside seller $(b=0)$. If the buyer chooses the continuation option, the price $p_{2}(\mu, y, z)$ to be negotiated depends on the relative bargaining power of the parties. ${ }^{12}$ What may transform the initial principal (buyer)-agent (seller) environment into a bilateral monopoly is transmission of information about the seller's (possibly improved) innate quality. We shall accordingly adopt a reduced-form bargaining solution to determine $p_{2}(\mu, y, z)$ whenever the relationship develops into a bilateral monopoly. The bargaining set containing $p_{2}(\mu, y, z)$ is $\left[c, c+\left(\theta_{\mathrm{H}}-\right.\right.$ $\left.\left.\theta_{\mathrm{L}}\right)(\mu-\pi)+f(y, z)\right] .^{13}$ When this set is nonempty, we make three natural assumptions about the negotiated price $p_{2}(\mu, y, z)$ :

- (A1) Ex ante efficiency (no expected surplus is lost).

- (A2) There is a unique outcome $p_{2}(\mu, y, z)$ that can be anticipated in advance (focal point).

- (A3) $p_{2}(\mu, y, z)$ is increasing in all its arguments.

Assumption (A1) is implicit in the construction of the bargaining set. (A2) allows us to use backwards induction techniques in solving for the equilibrium of the overall game. The justification for (A3) lies in the impact of $\mu, y$ and $z$ on the upper bound of the bargaining set, which is increasing in $\mu, y$ and $z$. Assumption (A3) thus merely states that the incumbent seller's share is strongly monotonic in the total expected continuation surplus. In Section 4 we shall impose a pro-

\footnotetext{
${ }^{12}$ To be specific about bargaining power, we attribute all the bargaining power to party A if, besides party $\mathrm{B}$, there exists at least one other observationally identical agent who is available for trade with party A, and if this condition does not obtain if the parties' names are exchanged. In this case, A can induce Bertrand-type competition among the agents including B and capture the whole surplus from trade. An absolute monopoly power cannot be justified otherwise, and we will accordingly assume that $\mathrm{A}$ and $\mathrm{B}$ have each some bargaining power that allows them to capture a portion of the gains from trade.

${ }^{13}$ To see this, note that if the buyer terminates the relationship and switches to another seller at the end of period one, her optimal offer is a price that leaves all seller types indifferent, that is, $p_{2}=c$. The buyer's disagreement utility is therefore $U_{\mathrm{B}}^{\mathrm{d}}=\pi \theta_{\mathrm{H}}+(1-\pi) \theta_{\mathrm{L}}-c$, while continuation at a price $p_{2}$ yields $\mu \theta_{\mathrm{H}}+(1-\mu) \theta_{\mathrm{L}}+f(y, z)-p$. The incumbent seller's disagreement utility is worth zero, therefore any price $p_{2}$ above $c$ for the second contract yields him a surplus. Obviously, if no type information is signaled nor any quality-improving investment is made, the incumbent seller is still identical from the buyer's viewpoint to outsiders $(\mu=\pi)$ and the bargaining set consists of just one point: $p_{2}=c$. Then the buyer continues to retain all the bargaining power. On the other hand, if $y=z=0$ and the seller reveals a low-quality type, then $\mu=0$ and the bargaining set is empty. It then follows that the buyer's switching option dominates. Our assumption that the number of potential sellers is large implies that the impact of termination on the distribution of seller types outside is negligible. Thus the probability that a randomly selected outside seller is of type $\theta_{\mathrm{H}}$ almost remains the same and equal to $\pi$ at the interim contract renewal stage. The analysis of the case of a small number of potential sellers with potential feedback on market distribution of seller types, as a referee has pointed out, is important and interesting but beyond the scope of this paper.
} 
portionality condition on the bargaining solution, a special case of which is the Nash bargaining solution.

Let us now move back to the initial contract stage where, as shown in Fig. 1, the buyer makes the initial contract offer. ${ }^{14}$ To obtain the expressions of the parties' expected utilities, given a first-period contract $\left\{p_{1}\right\}$, fix a strategy profile $\left\{\left(x_{\mathrm{i}}, y_{\mathrm{i}}\right)\right.$, $z\}$, where $\mathrm{i}=\mathrm{H}, \mathrm{L}$ and let $\mu \in[0,1]$ be the updated buyer beliefs at the contract renewal stage. Assuming no discounting, under these strategies the $\theta_{\mathrm{i}}$-seller's expected utility is

$$
U_{\mathrm{S}_{\mathrm{i}}}=p_{1}-c-d\left(x_{\mathrm{i}}\right)-y_{\mathrm{i}}+b\left(p_{2}\left(\mu, y_{\mathrm{i}}, z\right)-c\right)
$$

On the other hand, the buyer's expected utility is

$$
U_{\mathrm{B}}=q_{1}^{\mathrm{E}}-p_{1}-z+b\left[q_{2}^{\mathrm{E}}-p_{2}\left(\mu, y_{\mathrm{i}}, z\right)\right]+(1-b)\left[\pi \theta_{\mathrm{H}}+(1-\pi) \theta_{\mathrm{L}}-c\right]
$$

where $q_{1}^{\mathrm{E}}$ and $q_{2}^{\mathrm{E}}$ are the first- and second-period expected qualities. The firstperiod expected quality depends on the type (thus, potentially, on $\pi$ ) and the effort strategy of the incumbent seller. When the buyer continues with the same seller, the second-period expected quality depends on the buyer's updated beliefs and the investment decisions (made simultaneously in period one). These factors affecting quality in turn depend on the type of equilibrium induced by the initial contract offer $\left\{p_{1}\right\}$.

We require the parties' strategies to form a Perfect Bayesian Equilibrium $(\mathrm{PBE})^{15}$ and postulate the interim revised beliefs as follows: $\mu\left(\theta_{\mathrm{H}} \mid q_{1}, y\right)=1$ if both $q_{1} \geqslant \bar{q}$ and $y \geqslant \bar{y}, \mu\left(\theta_{\mathrm{H}} \mid q_{1}, y\right)=0$ otherwise, where $\bar{q}$ and $\bar{y}$ are to be determined. Thus, a quality or investment below $\bar{q}$ or $\bar{y}$ leads the buyer to believe that she faces a $\theta_{L}$-seller. ${ }^{16}$ The PBE concept requires that the belief system be consistent with strategies. In addition, we impose a refinement on beliefs off the equilibrium path, the Cho-Kreps Intuitive Criterion.

We classify potential PBE according to whether the buyer's initial contract offer performs screening and according to whether the two seller types 'separate' or 'pool' at the end of period one. We show below that any PBE satisfying the

\footnotetext{
${ }^{14}$ The results go through if contract proposals are instead made by the sellers, because competition between sellers at the outset ensures that the buyer's most preferred contract will be proposed, hence accepted.

${ }^{15}$ The buyer's continuation decision must be optimal, given her Bayesian-updated beliefs based upon observed first-period quality and investments, and investment decisions during the first period must be best replies to each other. Moving one step back in the sequence of events, the incumbent seller's contract acceptance and effort strategies must be optimal. Finally, the buyer chooses the contractual arrangement that maximizes Eq. (2). We make a standard tie-breaking assumption, according to which a $\theta_{\mathrm{L}}$-seller rejects a contract proposal if he is indifferent between accepting and rejecting.

${ }^{16}$ The partitions of the quality and investment range as postulated in the buyer's belief system are quite natural, because the $\theta_{\mathrm{H}}$-seller can provide any quality and investment that the $\theta_{\mathrm{L}}$-seller does.
} 
Intuitive Criterion is of the separating type, which leaves us with two potential types of PBE, screening/separating and nonscreening/separating. In the first type of PBE the buyer keeps only the $\theta_{\mathrm{H}}$-seller for the second period, in the second type of PBE she keeps both.

\section{Equilibria under short-term contracts}

The buyer's continuation decision when the first contract expires is $b^{*}=1$ if $q_{2}^{\mathrm{E}}-p_{2}\left(\mu, y_{\mathrm{i}}, z\right) \geqslant \pi \theta_{\mathrm{H}}+(1-\pi) \theta_{\mathrm{L}}-c$ and $b=0$ otherwise. Note that $b^{*}=1$ if $\mu=1{ }^{17}$ The buyer will continue with the seller who she knows to be of type $\theta_{\mathrm{L}}$ only if her continuation utility exceeds her outside option utility, that is, only if

$$
\frac{f\left(y_{\mathrm{L}}, z\right)-\left[p_{2}\left(0, y_{\mathrm{L}}, z\right)-c\right]}{\pi}>\theta_{\mathrm{H}}-\theta_{\mathrm{L}}
$$

This condition is likely to hold if $\pi$ is low (matching with a $\theta_{\mathrm{H}}$-seller after a switch is sufficiently unlikely), if the innate quality differential is small (trying an outside seller is not worthwhile), if the investments $y_{\mathrm{L}}$ and $z$ generate a sufficient improvement in $\theta_{\mathrm{L}}$, or if the seller's bargaining power is not too large (so that $p_{2}$ is not too large to make switching a better option for the buyer).

We consider first a nonscreening/separating $P B E$ with continuation to period two. Some important properties of such a PBE are the following: (i) the initial contract is accepted by both seller types; (ii) $b^{*}=1$ for all $\mu \in[0,1]$, which means that the buyer opts for continuation with both seller types; (iii) the seller types' first-period strategies are different (separating), so ( $x_{\mathrm{i}}^{*}, y_{\mathrm{i}}^{*}$ ) leads to either $\mu=1$ (if $\mathrm{i}=\mathrm{H}$ ) or $\mu=0$ (if $\mathrm{i}=\mathrm{L}$ ); (iv) given (i)-(iii), the expected second-period quality as viewed from the beginning of the relationship is

$$
q_{2}^{\mathrm{E}}=\pi\left[\theta_{\mathrm{H}}+f\left(y_{\mathrm{H}}^{*}, z^{*}\right)\right]+(1-\pi)\left[\theta_{\mathrm{L}}+f\left(y_{\mathrm{L}}^{*}, z^{*}\right)\right]
$$

and the expected first-period quality is

$$
q_{1}^{\mathrm{E}}=\pi\left[\theta_{\mathrm{H}}+x_{\mathrm{H}}^{*}\right]+(1-\pi)\left[\theta_{\mathrm{L}}+x_{\mathrm{L}}^{*}\right]
$$

The equilibrium investment and effort strategies $y_{i}^{*}, z^{*}, x_{i}^{*}$ are analyzed below. Assuming Eq. (3) so that in equilibrium the buyer sets $b^{*}=1$ with both seller types, the incumbent seller and the buyer's expected utilities as viewed from the stage of investment decisions are, respectively

$$
U_{\mathrm{S}_{\mathrm{i}}}^{\mathrm{I}}=\left[p_{2}\left(\mu, y_{\mathrm{i}}, z\right)-c\right]-y_{\mathrm{i}} \quad \text { and } \quad U_{\mathrm{B}}^{\mathrm{I}}=\left[q_{2}^{\mathrm{E}}-p_{2}\left(\mu, y_{\mathrm{i}}, z\right)\right]-z
$$

\footnotetext{
${ }^{17}$ This is so even in the absence of investment possibilities $(y=z=0)$, because the bargaining set to which $p_{2}(1,0,0)$ belongs has positive measure: $\left[c, c+\left(\theta_{\mathrm{H}}-\theta\right)(1-\pi)\right]$.
} 
Given the buyer's investment strategy $z^{*}$, in a separating equilibrium the $\theta_{\mathrm{H}^{-}}$ seller's investment strategy maximizes $U_{\mathrm{S}_{\mathrm{H}}}^{\mathrm{I}}$ where $\mu=1 .^{18}$ That is,

$$
\frac{\partial p_{2}\left(1, y_{\mathrm{H}}^{*}, z^{*}\right)}{\partial y}=1
$$

is the condition for optimality of $y_{\mathrm{H}}^{*}>0$. We assume that such a $y^{*}$ exists and $p_{2}(1$, $\left.y_{\mathrm{H}}^{*}, z^{*}\right)-c \geqslant y_{\mathrm{H}}^{*}{ }^{19}$ The $\theta_{\mathrm{L}}$-seller's investment strategy $y_{\mathrm{L}}^{*}$ maximizes $U_{\mathrm{S}_{\mathrm{L}}}^{\mathrm{I}}$ where $\mu=0$, thus satisfies

$$
y_{\mathrm{L}}^{*}>0 \quad \text { if } \quad \frac{\partial p_{2}\left(0, y_{\mathrm{L}}^{*}, z^{*}\right)}{\partial y}=1 \quad \text { and } \quad p_{2}\left(0, y_{\mathrm{L}}^{*}, z^{*}\right)-c \geqslant y_{\mathrm{L}}^{*}
$$

and $y_{\mathrm{L}}^{*}=0$ otherwise. According to the second condition in Eq. (5), the option of choosing a positive investment and lock the buyer in for the second period to negotiate the price $p_{2}\left(0, y_{\mathrm{L}}^{*}, z^{*}\right)$ yields a positive expected return, hence dominates the option of investing zero. In a nonscreening/separating PBE with continuation to the second period, the buyer invests $z^{*}$ on the incumbent seller's innate quality under incomplete information. Thus $z^{*}$ maximizes $U_{\mathrm{B}}^{\mathrm{I}}$ where $b=1$, which implies

$$
\begin{aligned}
& \pi \frac{\partial f\left(y_{\mathrm{H}}^{*}, z^{*}\right)}{\partial z}+(1-\pi) \frac{\partial f\left(y_{\mathrm{L}}^{*}, z^{*}\right)}{\partial z}-\pi \frac{\partial p_{2}\left(1, y_{\mathrm{H}}^{*}, z^{*}\right)}{\partial z}-(1-\pi) \frac{\partial p_{2}\left(0, y_{\mathrm{L}}^{*}, z^{*}\right)}{\partial z} \\
& =1
\end{aligned}
$$

The first two terms in Eq. (6) represent the expected marginal benefit of improved seller quality for the second period. The next two terms represent a cost in the form of a higher expected second-period price, because investments improve innate quality, hence by Assumption (A3), the bargaining power of the incumbent seller.

As for the equilibrium effort strategies, the $\theta_{\mathrm{L}}$-seller obviously has nothing to gain by exerting any effort in a nonscreening PBE, thus $x_{\mathrm{L}}^{*}=0$. However, despite noncontractibility of quality, the $\theta_{\mathrm{H}}$-seller may have to signal his type by exerting positive effort, provide a sufficiently high first-period quality and make an investment which the $\theta_{\mathrm{L}}$-seller cannot beneficially imitate. It is optimal for the

\footnotetext{
${ }^{18}$ We assume that $U_{\mathrm{S}_{\mathrm{i}}}^{\mathrm{I}}$ and $U_{\mathrm{B}}^{\mathrm{I}}$ are concave in $y_{\mathrm{i}}$ and $z$, respectively, so that the first-order conditions below are necessary and sufficient. Given strict concavity of $f(y, z), U_{\mathrm{s}_{\mathrm{i}}}^{\mathrm{I}}$ is concave in $y_{\mathrm{i}}$ if $p_{2}\left(\mu, y_{\mathrm{i}}, z\right)$ is concave in $y_{\mathrm{i}}$, which is implied if the seller's share of the second-period surplus is not increasing too disproportionately in his own investment $y_{\mathrm{i}}$. On the other hand, $q_{2}^{\mathrm{E}}$ is made up of two components, the expected innate quality and the expected quality improvement due to investments according to the strictly concave function $f(y, z)$. Thus $U_{\mathrm{B}}^{\mathrm{I}}$ is concave in $z$ if $p_{2}\left(\mu, y_{\mathrm{i}}, z\right)$ is convex (or not too concave) in $z$, which is implied if the buyer's share from the second-period surplus is not increasing too disproportionately in her own investment $z$. These conditions are satisfied by the proportional solution considered in Section 4.

${ }^{19}$ This amounts to assuming that $\partial p_{2}\left(l, 0, z^{*}\right) / \partial y>1$ for all $z^{*}$ in the relevant range.
} 
$\theta_{\mathrm{H}}$-seller to signal by exerting the 'minimal' effort level that makes the $\theta_{\mathrm{L}}$-seller indifferent between imitating the strategy of a $\theta_{\mathrm{H}}$-seller and playing his own strategy $\left(x_{\mathrm{L}}^{*}=0, y_{\mathrm{L}}^{*}\right)$. The imitation strategy promises the $\theta_{\mathrm{L}}$-seller the net gain $N G=p_{2}\left(1, y_{\mathrm{H}}^{*}, z^{*}\right)-y_{\mathrm{H}}^{*}-\left(p_{2}\left(0, y_{\mathrm{L}}^{*}, z^{*}\right)-y_{\mathrm{L}}^{*}\right)$. Thus the $\theta_{\mathrm{L}}$-seller would be willing to exert effort up to $\bar{x}_{\mathrm{L}}$, if this leads the buyer to believe $\mu=1$, such that $d\left(\bar{x}_{\mathrm{L}}\right)=N G$, hence $\bar{x}_{\mathrm{L}}=\phi(N G)$ where $\phi($.$) denotes the inverse of d($.$) . If the effort$ $\bar{x}_{\mathrm{L}}$ falls short of the 'innate quality gap' $\theta_{\mathrm{H}}-\theta_{\mathrm{L}}$, then the $\theta_{\mathrm{H}}$-seller does not have to exert any effort to signal his type. Otherwise he must set $x_{\mathrm{H}}^{*}=\bar{x}_{\mathrm{L}}-\left(\theta_{\mathrm{H}}-\theta_{\mathrm{L}}\right)>$ 0 to avoid the risk of being mimicked by a $\theta_{\mathrm{L}}$-seller.

Proposition 1 characterizes the optimal contract $\left\{p_{1}^{*}\right\}$ inducing a nonscreening PBE.

Proposition 1. All PBE satisfying the Intuitive Criterion involve separation of seller types at the end of the first contract, and the first-period price is always below the cost $c$. In a nonscreening PBE with positive investments $y_{i}^{*}, z^{*}>0$ the buyer sets $b^{*}=1$ with both seller types if Eq. (3) holds, the $\theta_{L}$-seller chooses $x_{L}^{*}=0$ and the $\theta_{H^{-}}$seller signals his type through the effort $x_{H}^{*}=\max \left\{0, \bar{x}_{L}-\left(\theta_{H}-\right.\right.$ $\left.\left.\theta_{L}\right)\right\}$ where $\bar{x}_{L}=\phi\left(y_{L}^{*}-y_{H}^{*}+p_{2}\left(1, y_{H}, z^{*}\right)-p_{2}\left(0, y_{L}^{*}, z^{*}\right)\right)$, and the optimal first-period contract $\left\{p_{1}^{*}\right\}$ satisfies $p_{1}^{*}=2 c+y_{L}^{*}-p_{2}\left(0, y_{L}^{*}, z^{*}\right)$.

The Intuitive Criterion, applied to this game, eliminates all potential pooling PBE and implies separation of seller types at the end of the first contract. ${ }^{21}$ The optimal first contract $\left\{p_{1}^{*}\right\}$ binds the participation constraint of the $\theta_{\mathrm{L}}$-seller (who exerts $x_{\mathrm{L}}^{*}=0$ ), leaving the $\theta_{\mathrm{H}}$-seller with a surplus. It may indeed be optimal to induce such an equilibrium because the $\theta_{\mathrm{L}}$-seller also invests his part $y_{\mathrm{L}}^{*}$ to improve his innate quality. To be positive, the optimal investment of the $\theta_{\mathrm{L}}$-seller must generate sufficient improvements in the innate quality, hence, in the secondperiod price, so that the $\theta_{\mathrm{L}}$-seller covers at least the cost of investment. If the $\theta_{\mathrm{L}}$-seller expects a negative surplus from investing, he will choose $y_{\mathrm{L}}^{*}=0$, and if Eq. (3) does not hold for $y_{\mathrm{L}}=0$, continuation with the $\theta_{\mathrm{L}}$-seller is not beneficial. Then the nonscreening equilibrium price is $p_{1}=c$.

The buyer's alternative option at the outset is to induce a screening $P B E$ where the initial contract screens out $\theta_{\mathrm{L}}$-sellers but attracts $\theta_{\mathrm{H}}$-sellers with continuation to period two. The players' expected utilities now are given by Eq. (1) for the $\theta_{\mathrm{H}}$-seller and Eq. (2) for the buyer, where $b=1$ and $\mu=1$ in the expression of $p_{2}$. $\theta_{\mathrm{L}}$-sellers remain at their outside option and obtain zero.

\footnotetext{
${ }^{20}$ The proofs of Propositions 1 and 2 and Lemma 1 are in Appendix A.

${ }^{21}$ This is so, because given his innate quality advantage, the $\theta_{\mathrm{H}}$-seller always finds it beneficial to provide a quality and investment signal which the $\theta_{\mathrm{L}}$-seller cannot imitate, which should therefore convince the buyer that she faces a $\theta_{\mathrm{H}}$-seller.
} 
Along the path of a screening PBE the buyer makes her investment $\hat{z}$ under complete information, knowing that $\theta=\theta_{H}$. Thus, $\hat{z}$ satisfies

$$
\frac{\partial f\left(\hat{y}_{H}, \hat{z}\right)}{\partial z}-\frac{\partial p_{2}\left(1, \hat{y}_{H}, \hat{z}\right)}{\partial z}=1
$$

Condition (7) is the analogue of Eq. (6). As in the nonscreening PBE, the $\theta_{\mathrm{H}}$-seller's best reply $\hat{y}_{\mathrm{H}}$ to $\hat{z}$ satisfies the optimality condition (4): $\partial f\left(\hat{y}_{\mathrm{H}}\right.$, $\hat{z}) / \partial y=1$. Proposition 2 characterizes the optimal effort strategy of the $\theta_{\mathrm{H}}$-seller and provides a lower bound to the buyer's expected utility.

Proposition 2. In a screening PBE satisfying the Intuitive Criterion, the buyer offers $\hat{p}_{1}<c$, only $\theta_{H}$-sellers accept and exert the effort $\hat{x}_{H}=\max \left\{0, \bar{x}_{L}-\left(\theta_{H}-\right.\right.$ $\left.\left.\theta_{L}\right)\right\}$ where $\bar{x}_{L}=\phi\left(\hat{p}_{1}-2 c-\hat{y}_{H}+p_{2}\left(1, \hat{y}_{H}, \hat{z}\right)\right)$, if selected by the buyer. The expected utility of the buyer in a screening PBE is bounded below by $\underline{U}_{B}=2\left[\theta_{H}-\right.$ $c]+f\left(y_{H}, z\right)-y_{H}-z$, which she obtains by setting $\underline{p}_{1}=2 c+\hat{y}_{H}-p_{2}\left(1, \hat{y}_{H}, \hat{z}\right)$.

The utility $\underline{U}_{B}$ corresponds to the zero effort case $\hat{x}_{\mathrm{H}}=0$ where the buyer offers the price $p_{1}$, the lowest possible screening PBE price which binds the participation constraint of the $\theta_{\mathrm{H}}$-seller. The buyer may expect more than $\underline{U}_{B}$ because she may find it beneficial to induce positive effort. The reason why the $\theta_{\mathrm{H}}$-seller would exert effort in a screening $\operatorname{PBE}\left(\hat{x}_{\mathrm{H}}>0\right.$ if $\bar{x}_{\mathrm{L}}>\theta_{\mathrm{H}}-\theta_{\mathrm{L}}$ ) may be counterintuitive. Along the screening PBE path the buyer chooses her investment $\hat{z}$ under the belief that she faces a $\theta_{\mathrm{H}}$-seller (because only $\theta_{\mathrm{H}}$-sellers accept the initial contract). ${ }^{22}$ The $\theta_{\mathrm{H}}$-seller in turn invests his best reply $\hat{y}_{\mathrm{H}}$ and the parties negotiate the price $p_{2}(1$, $\hat{y}_{\mathrm{H}}, \hat{z}$ ) for the second period. If the $\theta_{\mathrm{H}}$-seller does not exert effort, a $\theta_{\mathrm{L}}$-seller who foresees this future path of play will consider accepting the initial contract, providing the quality $q_{1}=\theta_{\mathrm{H}}$ by exerting the effort $x_{\mathrm{L}}=\theta_{\mathrm{H}}-\theta_{\mathrm{L}}$ to close the innate quality gap, and investing $\hat{y}_{\mathrm{H}}$ to fully imitate the $\theta_{\mathrm{H}}$-seller. In fact, if the first-period price is sufficiently high, the $\theta_{\mathrm{L}}$-seller is willing to exert more than the

\footnotetext{
${ }^{22}$ We could have introduced additional notation to represent the buyer's updated beliefs at the initial contract acceptance stage. We have chosen not to, because only the updated beliefs at the contract renewal stage are payoff-relevant (they determine whether the relationship will go through the second period and, in the affirmative, the negotiated price). If the 'never dissuaded once convinced' assumption (see Harrington (1993) for a discussion and references to models that use it) were imposed on the buyer's beliefs, there would be no room for updating beliefs at the contract renewal stage once the buyer attributes probability one to the event $\theta=\theta_{\mathrm{H}}$ after observing the acceptance strategies. As a result, in a screening PBE the $\theta_{\mathrm{H}}$-seller would have no need to exert effort. We are not assuming here that the buyer is 'never dissuaded once convinced', for a good reason: The mere acceptance of a contract may not be a proof of a high innate quality unless it is supplemented by a sufficient first-period quality and investment.
} 
effort that just closes the innate quality gap, up to a higher effort $\bar{x}_{\mathrm{L}}$, provided this convinces the buyer that $\theta=\theta_{\mathrm{H}}$. The strategy pair $\left(\bar{x}_{\mathrm{L}}, \hat{y}_{\mathrm{H}}\right)$ is such that the $\theta_{\mathrm{L}}$-seller's expected imitation utility $U_{\mathrm{S}_{\mathrm{L}}}^{\mathrm{Im}}$ is equal to zero:

$$
U_{\mathrm{S}_{\mathrm{L}}}^{\mathrm{Im}}=p_{1}-c-d\left(\bar{x}_{\mathrm{L}}\right)-\hat{y}_{\mathrm{H}}+\left[p_{2}\left(1, \hat{y}_{\mathrm{H}}, \hat{z}\right)-c\right]=0
$$

This yields $\bar{x}_{\mathrm{L}}=\phi\left(p_{1}-2 c-\hat{y}_{\mathrm{H}}+p_{2}\left(1, \hat{y}_{\mathrm{H}}, \hat{z}\right)\right)$, as stated in Proposition 2. Given the possibility of imitation, the buyer would be convinced that she faces a $\theta_{\mathrm{H}}$-seller at the contract renewal stage only if first-period quality is above the 'quality imitation capacity' $\bar{q}=\bar{x}_{\mathrm{L}}+\theta_{\mathrm{L}}$ of a $\theta_{\mathrm{L}}$-seller. To meet this quality standard and avoid being imitated by a $\theta_{\mathrm{L}}$-seller, the $\theta_{\mathrm{H}}$-seller has to exert the effort $\hat{x}_{\mathrm{H}}=$ $\max \left\{0, x_{\mathrm{L}}-\left(\theta_{\mathrm{H}}-\theta_{\mathrm{L}}\right)\right\}$.

Should the buyer induce positive effort, hence get an improved quality in the screening PBE? First, this option has a cost in the form of a higher first-period price. Second, and more importantly, the higher first-period price may trigger a 'penetration' strategy from $\theta_{\mathrm{L}}$-sellers, hence upset the screening equilibrium. We take up these issues in order below.

A higher first-period price works its effect through the quality imitation capacity of $\theta_{\mathrm{L}}$-sellers, that is, through the effort $\bar{x}_{\mathrm{L}}$ defined implicitly by Eq. (8). Increasing $p_{1}$ induces competition by increasing $U_{\mathrm{S}_{\mathrm{L}}}^{\mathrm{Im}}$, hence the quality imitation capacity of $\theta_{\mathrm{L}}$-sellers, which leads the incumbent $\theta_{\mathrm{H}}$-seller to exert more effort and avoid being mimicked by a $\theta_{\mathrm{L}}$-seller. The buyer should increase $p_{1}$ until the marginal benefits and costs are equalized:

$$
\frac{\partial \phi\left(\hat{p}_{1}-2 c-\hat{y}_{\mathrm{H}}+p_{2}\left(1, \hat{y}_{\mathrm{H}}, \hat{z}\right)\right)}{\partial d}=1
$$

The left-hand side of Eq. (9) is in fact $\partial \bar{x}_{\mathrm{L}} / \partial p_{1}=\partial \hat{x}_{\mathrm{H}} / \partial p_{1}$, the additional effort (hence, quality) that the buyer gets for a dollar increase in the price.

However, the condition in Eq. (9) does not necessarily characterize the optimal $\hat{p}_{1}$ that induces a screening PBE with positive effort. The analysis above has ignored a potential 'penetration' strategy of $\theta_{\mathrm{L}}$-sellers: As $p_{1}$ is increased to efficiently induce a positive-effort screening $\mathrm{PBE}$, the $\theta_{\mathrm{L}}$-sellers may find it beneficial to accept the initial contract $\left\{\hat{p}_{1}\right\}$, exert zero effort and invest their best reply $y_{\mathrm{L}}(\hat{z})$ to $\hat{z}$. Observing this effort and investment strategy (which is not an imitation of the $\theta_{\mathrm{H}}$-seller's strategy) the buyer would revise her beliefs to $\mu=0$ but prefer continuation with the (improved) $\theta_{\mathrm{L}}$-seller if Eq. (3) holds for $y_{\mathrm{L}}=y_{\mathrm{L}}(\hat{z})$, $z=\hat{z}$. Thus, if Eq. (3) holds, this 'penetration' strategy yields the $\theta_{\mathrm{L}}$-seller the utility $U_{\mathrm{S}_{\mathrm{L}}}^{\mathrm{P}}=p_{1}-c-y_{\mathrm{L}}(\hat{z})+\left[p_{2}\left(0, y_{\mathrm{L}}(\hat{z}), \hat{z}\right)-c\right]$, which defines the 'maximal screening price' $\bar{p}_{1}=2 c+y_{\mathrm{L}}(\hat{z})-p_{2}\left(0, y_{\mathrm{L}}(\hat{z}), \hat{z}\right)$. At any price above $\bar{p}_{1}, U_{\mathrm{S}_{\mathrm{L}}}^{\mathrm{P}}>$ 0 , hence the buyer cannot induce a screening PBE. Two cases arise, depending on how the optimal $\hat{p}_{1}$ satisfying Eq. (9) compares with respect to $\bar{p}_{1}$. If $\hat{p}_{1}$ does not exceed $\bar{p}_{1}$, nothing to worry. Then the buyer can induce the efficient effort level 
with no fear of penetration from $\theta_{\mathrm{L}}$-sellers. We have $\hat{p}_{1} \leqslant \bar{p}_{1}$ if the left-hand side of Eq. (9), evaluated at $\hat{p}_{1}=\bar{p}_{1}$, is smaller than one, that is, if ${ }^{23}$

$$
\frac{\partial \phi\left(y_{\mathrm{L}}(\hat{z})-\hat{y}_{\mathrm{H}}+p_{2}\left(1, \hat{y}_{\mathrm{H}}, \hat{z}\right)-p_{2}\left(0, y_{\mathrm{L}}(\hat{z}), \hat{z}\right)\right)}{\partial d} \leqslant 1
$$

which yields the buyer the expected utility

$$
\hat{U}_{\mathrm{B}}=\theta_{\mathrm{H}}+\hat{x}_{\mathrm{H}}-\hat{p}_{1}-\hat{z}+\left[\theta_{\mathrm{H}}+f\left(\hat{y}_{\mathrm{H}}, \hat{z}\right)-p_{2}\left(1, \hat{y}_{\mathrm{H}}, \hat{z}\right)\right]
$$

If $\hat{p}_{1}>\bar{p}_{1}$ (hence, if the inequality in Eq. (10) is reversed), the buyer has to set $\hat{p}_{1}>\bar{p}_{1}$ and sacrifice from the efficiency of the screening process. The problem that we stress is that this price may be too low and induce very little effort, if any. As a result the buyer's expected utility in Eq. (11) evaluated at $\hat{p}_{1}>\bar{p}_{1}$ may fall below $\underline{U}_{\mathrm{B}}$. Then the buyer will induce a screening PBE with zero effort and obtain $\underline{U}_{\mathrm{B}}$. This bad outcome is the product of the conflict between the buyer's motive of efficient screening and her investment incentives. We explore this potential conflict further below.

The following lemma ranks three prices, the nonscreening PBE price $p_{1}^{*}$, the zero-effort screening PBE price $\underline{p}_{1}$, and the maximal screening price $\bar{p}_{1}$.

Lemma 1. $p_{1}^{*}>\underline{\hat{p}}_{1}$, and $p_{1}^{*} \geqslant \bar{p}_{1}$ if $z^{*} \leqslant \hat{z}$.

That $p_{1}^{*}$ is always higher than $\hat{p}_{1}$ is to be expected because these two prices are set to bind the participation constraints of the $\theta_{H}$-seller who exerts zero effort and the $\theta_{\mathrm{H}}$-seller who exerts zero effort, respectively, in a nonscreening and a screening PBE. The comparison between $p_{1}^{*}$ and $\bar{p}_{1}$ hinges on the relative sizes of buyer investments in the two types of PBE. ${ }^{24}$ We have $p_{1}^{*} \geqslant \bar{p}_{1}$ if $z^{*} \leqslant \hat{z}, p_{1}^{*}<p_{1}$, otherwise. The intuition is simple: In the nonscreening PBE, given the buyer's investment $z^{*}, p_{1}^{*}$, binds the participation constraint of the $\theta_{\mathrm{L}}$-seller. Keeping the price at $p_{1}^{*}$, if the buyer's screening PBE investment $\hat{z}$ exceeds $z^{*}$, then the $\theta_{\mathrm{L}}$-sellers' expected utility from playing the penetration strategy would be positive (because a higher investment increases the continuation surplus, hence the secondperiod price). Therefore, if $\hat{z} \geqslant z^{*}$ the maximal screening price $\bar{p}_{1}$ should be lower than $p_{1}^{*}$ to bind the participation constraint of the $\theta_{\mathrm{L}}$-seller (who is indifferent

\footnotetext{
${ }^{23}$ That condition (10) implies $p_{1} \leqslant \bar{p}_{1}$ follows from strict concavity of $\phi(d)$, the inverse of the strictly convex effort disutility function $d(x)$.

${ }^{24}$ This comparison is important because if the optimal nonscreening price $p_{1}^{*}$ is lower than the maximal screening price, there may be a range of prices $\left[p_{1}^{*}, \bar{p}_{1}\right]$ that induce both screening and nonscreening equilibria. If, on the other hand, $p_{1}^{*} \geqslant \bar{p}_{1}$ then the only constraint that the buyer faces in increasing $p_{1}$ in a screening PBE is the maximal screening price $\bar{p}_{1}$, beyond which the screening PBE is upset by the 'penetration' strategy of $\theta_{\mathrm{L}}$-sellers.
} 
between staying out and penetrating in). The discussion above is sharpened in the following proposition.

Proposition 3. Assume $\hat{z} \geqslant z^{*}$, thus, $\bar{p}_{1} \leqslant p_{1}^{*}$. If Eq. (10) does not hold (i.e., if $\left.\bar{p}_{1}<\hat{p}_{1}\right)$, the buyer has to distort the optimal positive-effort screening PBE price $\hat{p}_{1}$ down and induce a lower effort. Then, the buyer's expected utility $\hat{U}_{B}=\theta_{H}+$ $\hat{x}_{H}-\hat{p}_{1}-\hat{z}+\left[\theta_{H}+f\left(\hat{y}_{H}, \hat{z}\right)-p_{2}\left(1, \hat{y}_{H}, \hat{z}\right)\right]$ in the positive-effort screening PBE falls below $\underline{U}_{B}$ if $\hat{p}_{1}+p_{2}\left(1, \hat{y}_{H}, \hat{z}\right)-\hat{x}_{H}>2 c+\hat{y}_{H}$, which leads her to induce an inefficient, zero-effort screening $P B E$.

Proposition 3 highlights the potential conflict we mentioned in Section 1, between the goal of efficient screening and the presence of an investment technology that improves the seller's innate quality. In the next section we show that if the outcome of bargaining over the second period price is a proportional solution, then $\hat{z}=z^{*}$ and by Proposition 3, it is sufficient to check condition (10), that is, whether $\hat{p}_{1}<\bar{p}_{1}$, to see whether the buyer is able to induce the efficient effort in a screening PBE.

\section{Proportional solutions to the second-period bargaining problem}

The class of solutions to the negotiation problem considered in this section splits the continuation surplus, if positive, in fixed proportions. The share $\alpha$ goes to the incumbent seller, and the share $1-\alpha$ goes to the buyer. The case of proportional solutions is simple, relatively tractable, and displays relatively clearly the potential conflict between investment incentives and efficient screening. Note that the case $\alpha=1 / 2$ corresponds to the Nash bargaining solution. ${ }^{25}$

Given a pair of investment strategies, the continuation surplus is $f(y, z)+(1-$ $\pi)\left(\theta_{\mathrm{H}}-\theta_{\mathrm{L}}\right)$ if $\mu=1$, and $f(y, z)-\pi\left(\theta_{\mathrm{H}}-\theta_{\mathrm{L}}\right)$ if $\mu=0$. The second-period prices split the surplus according to the proportional solution, hence are given by

$$
\begin{aligned}
& p_{2}(1, y, z)=\alpha\left[f(y, z)+(1-\pi)\left(\theta_{\mathrm{H}}-\theta_{\mathrm{L}}\right)\right]+c \quad \text { and } \\
& p_{2} f(0, y, z)=\alpha\left[f(y, z)-\pi\left(\theta_{\mathrm{H}}-\theta_{\mathrm{L}}\right)\right]+c,
\end{aligned}
$$

for $\mu=1$ and $\mu=0$, respectively. We shall use the price expressions above in the conditions derived in Section 3 to characterize the PBE satisfying the Intuitive Criterion.

We consider first the nonscreening $P B E$. When $p_{2}\left(0, y_{\mathrm{L}}, z\right)$ is given by Eq. (12),

\footnotetext{
${ }^{25}$ In an axiomatic framework, Kalai (1977) views invariance of the outcome with respect to the 'agenda' as a desirable property and shows that the proportional solution is the only agenda-invariant solution.
} 
condition (3) which stipulates continuation with the $\theta_{\mathrm{L}}$-seller simplifies to $f\left(y_{\mathrm{L}}\right.$, $z)>\pi\left(\theta_{\mathrm{H}}-\theta_{\mathrm{L}}\right)$. Recall that in a nonscreening PBE the $\theta_{\mathrm{L}}$-seller exerts zero effort, thus obtains the expected utility $U_{\mathrm{S}_{\mathrm{L}}}^{*}=p_{1}^{*}-c-y_{\mathrm{L}}^{*}+\alpha\left[f\left(y_{\mathrm{L}}^{*}, z^{*}\right)-1-\pi\left(\theta_{\mathrm{H}}-\right.\right.$ $\left.\theta_{\mathrm{L}}\right)$ ]. On the other hand, the $\theta_{\mathrm{H}}$-seller may exert effort to signal his type and obtain $U_{\mathrm{S}_{\mathrm{H}}}^{*}=p_{1}^{*}-c-d\left(x_{\mathrm{H}}^{*}\right)-y_{\mathrm{H}}^{*}+\alpha\left[f\left(y_{\mathrm{H}}^{*}, z^{*}\right)+(1-\pi)\left(\left(\theta_{\mathrm{H}}-\theta_{\mathrm{L}}\right)\right]\right.$. These expected utilities yield the same first-order condition for $y_{\mathrm{H}}^{*}$ and $y_{\mathrm{L}}^{*}:{ }^{26}$

$$
1=\alpha \partial f\left(y_{\mathrm{i}}^{*}, z\right) / \partial y, \quad i=\mathrm{L}, \mathrm{H}
$$

Therefore, $y_{\mathrm{H}}^{*}=y_{\mathrm{L}}^{*}$. The second- and first-period expected qualities are, respectively $q_{2}^{\mathrm{E}}=\pi \theta_{\mathrm{H}}+(1-\pi) \theta_{\mathrm{L}}+f\left(y_{\mathrm{i}}^{*}, z^{*}\right)$ and $q_{1}^{\mathrm{E}}=\pi\left(x_{\mathrm{H}}^{*}+\theta_{\mathrm{H}}\right)+(1-\pi) \theta_{\mathrm{L}}$. Since the relationship extends to the second period no matter the type of the incumbent seller, in a nonscreening PBE the buyer expects to pay the price $\pi p_{2}\left(1, y_{i}^{*}\right.$, $\left.z^{*}\right)+(1-\pi) p_{2}\left(0, y_{i}^{*}, z^{*}\right)$ in the second period, which, using Eq. (12), simplifies to $p_{2}^{\mathrm{E}}=\alpha f\left(y_{\mathrm{i}}^{*}, z^{*}\right)+c$. Therefore, the buyer's expected utility $U_{\mathrm{B}}^{*}=q_{1}^{\mathrm{E}}-p_{1}^{*}-$ $z^{*}+\left[q_{2}^{\mathrm{E}}-p_{2}^{\mathrm{E}}\right]$ can be written as

$$
\begin{aligned}
U_{\mathrm{B}}^{*}= & \pi\left(x_{\mathrm{H}}^{*}+\theta_{\mathrm{H}}\right)+(1-\pi) \theta_{\mathrm{L}}-p_{1}^{*}-z^{*}+\left[\pi \theta_{\mathrm{H}}+(1-\pi) \theta_{\mathrm{L}}+f\left(y_{\mathrm{i}}^{*}, z^{*}\right)\right] \\
& -\left[\alpha f\left(y_{\mathrm{i}}^{*}, z^{*}\right)+c\right]
\end{aligned}
$$

The buyer's optimal investment $z^{*}$ maximizes $U_{\mathrm{B}}^{*}$, that is, satisfies $1=(1-$ $\alpha) \partial f\left(y_{i}^{*}, z^{*}\right) / \partial z$. Finally, since in a nonscreening PBE the optimal first-period price binds the participation constraint of the $\theta_{\mathrm{L}}$-seller, $p_{1}^{*}=c+y_{\mathrm{i}}^{*}-\alpha\left[f\left(y_{\mathrm{i}}^{*}\right.\right.$, $\left.\left.z^{*}\right)-\pi\left(\theta_{\mathrm{H}}-\theta_{\mathrm{L}}\right)\right]$. Using this fact, we can write the buyer's nonscreening PBE expected utility as

$$
U_{\mathrm{B}}^{*}=2\left[\pi \theta_{\mathrm{H}}+(1-\pi) \theta_{\mathrm{L}}-c\right]+f\left(y_{\mathrm{i}}^{*}, z^{*}\right)-\pi \alpha\left(\theta_{\mathrm{H}}-\theta_{\mathrm{L}}\right)+\pi x_{\mathrm{H}}^{*}-z^{*}-y_{\mathrm{i}}^{*}
$$

Consider now a screening $P B E$, where only $\theta_{\mathrm{H}}$-sellers apply and the buyer continues with the incumbent $\theta_{\mathrm{H}}$-seller. The second-period price and quality are now $\hat{p}_{2}=\alpha\left[f\left(\hat{y}_{\mathrm{H}}, \hat{z}\right)+(1-\pi)\left(\theta_{\mathrm{H}}-\theta_{\mathrm{L}}\right)\right]+c$ and $\hat{q}_{2}=\theta_{\mathrm{H}}+f\left(\hat{y}_{\mathrm{H}}, \hat{z}\right)$. Using this $\hat{p}_{2}$ in the expected utility of the $\theta_{\mathrm{H}}$-seller and maximizing with respect to $y_{\mathrm{H}}$, we find that his investment strategy $y_{\mathrm{H}}$ in a screening PBE is determined through the same condition as in a nonscreening PBE: $\alpha \partial f\left(\hat{y}_{\mathrm{H}}, z\right) / \partial y=1$. Quality in the first period will be $q_{1}^{\mathrm{E}}=\theta_{\mathrm{H}}+\hat{x}_{\mathrm{H}}$, thus the buyer's expected utility can be expressed as follows:

$$
\begin{aligned}
\hat{U}_{\mathrm{B}}= & \theta_{\mathrm{H}}+\hat{x}_{\mathrm{H}}-\hat{p}_{1}-\hat{z} \\
& +\left\{\theta_{\mathrm{H}}+f\left(\hat{y}_{\mathrm{H}}, \hat{z}\right)-\alpha\left[f\left(\hat{y}_{\mathrm{H}}, \hat{z}\right)+(1-\pi)\left(\theta_{\mathrm{H}}-\theta_{\mathrm{L}}\right)\right]-c\right\}
\end{aligned}
$$

The optimal investment $\hat{z}$ of the buyer maximizes this expression, thus satisfies

\footnotetext{
${ }^{26}$ The second-order conditions hold thanks to strict concavity of $f(.,$.$) .$
} 
$(1-\alpha) \partial f\left(y_{\mathrm{H}}, z\right) / \partial z=1$. To induce a zero-effort screening PBE the buyer offers the price $\underline{p}_{1}=\hat{y}_{\mathrm{H}} c-\alpha\left[f\left(\hat{y}_{\mathrm{H}}, \hat{z}\right)+(1-\pi)\left(\theta_{\mathrm{H}}-\theta_{\mathrm{L}}\right)\right]$ which binds the participation constraint of the $\theta_{\mathrm{H}}$-seller and yields the buyer her lower bound utility

$$
\underline{U}_{\mathrm{B}}=2\left(\theta_{\mathrm{H}}-c\right)-\hat{y}_{\mathrm{H}}-\hat{z}+f\left(\hat{y}_{\mathrm{H}}, \hat{z}\right) .
$$

Let us now derive the maximal screening price $\bar{p}_{1}$. If a $\theta_{\mathrm{L}}$-seller accepts the initial contract and invests his best reply $y_{\mathrm{L}}(\hat{z})$ to $\hat{z}$ and if Eq. (3) holds so that, he locks the buyer in for the second period. The $\theta_{\mathrm{L}}$-seller's expected utility from playing this penetration strategy is

$$
U_{\mathrm{S}_{\mathrm{L}}}^{\mathrm{P}}=p_{1}-c-y_{\mathrm{L}}(\hat{z})+\alpha\left[f\left(y_{\mathrm{L}}(\hat{z}), \hat{z}\right)-\pi\left(\theta_{\mathrm{H}}-\theta_{\mathrm{L}}\right)\right] .
$$

Observe that $\hat{y}_{\mathrm{H}}=y_{\mathrm{L}}(\hat{z})$ because under the proportional solution $y_{\mathrm{L}}(z)$ satisfies the same first-order condition as $\hat{y}_{\mathrm{H}}: \alpha \partial f\left(y_{\mathrm{L}}(\hat{z}), \hat{z}\right) / \partial y_{\mathrm{L}}=1$. The maximal screening price $\bar{p}_{1}$ makes the $\theta_{\mathrm{L}}$-sellers indifferent between playing the penetration strategy and staying at their outside option, thus satisfies $\hat{U}_{\mathrm{S}_{\mathrm{L}}}^{\mathrm{P}}=0$ :

$$
\bar{p}_{1}=c+\hat{y}_{\mathrm{H}}+\alpha \pi\left(\theta_{\mathrm{H}}-\theta_{\mathrm{L}}\right)-\alpha f\left(\hat{y}_{\mathrm{H}}, \hat{z}\right)
$$

using the fact that $\hat{y}_{\mathrm{H}}=y_{\mathrm{L}}(\hat{z})$. Note that $\bar{p}_{1}>\underline{p}_{1}$. We consider now the buyer's option of inducing a screening PBE with positive effort. To this end, the buyer has to increase $p_{1}$ sufficiently above $\bar{p}_{1}$. As we have shown in Section 3 , to have positive effort $\hat{x}_{\mathrm{H}}>0$ in a screening PBE satisfying the Intuitive Criterion, we need $\bar{x}_{\mathrm{L}}>\theta_{\mathrm{H}}-\theta_{\mathrm{L}}$, where $\hat{x}_{\mathrm{L}}$ is the quality imitation capacity of a $\theta_{\mathrm{L}}$-seller, defined implicitly through his indifference between imitating the strategy of a $\theta_{\mathrm{H}}$-seller and staying out:

$$
\hat{U}_{\mathrm{S}_{\mathrm{L}}}^{\mathrm{Im}}=p_{1}-d\left(\bar{x}_{\mathrm{L}}\right)-c-\hat{y}_{\mathrm{H}}+\alpha\left[f\left(\hat{y}_{\mathrm{H}}, z\right)+(1-\pi)\left(\theta_{\mathrm{H}}-\theta_{\mathrm{L}}\right)\right]=0
$$

This yields $\bar{x}_{\mathrm{L}}=\phi\left(p_{1}-c-\hat{y}_{\mathrm{H}}+\alpha f\left(\hat{y}_{\mathrm{H}}, \hat{z}\right)+\alpha(1-\pi)\left(\theta_{\mathrm{H}}-\theta_{\mathrm{L}}\right)\right)$. The optimal level of effort would be induced if the price $\hat{p}_{1}$ is increased until the marginal benefits and costs are equalized, thus

$$
\frac{\partial \phi\left(\hat{p}_{1}-c-\hat{y}_{\mathrm{H}}+\alpha f\left(\hat{y}_{\mathrm{H}}, \hat{z}\right)+\alpha(1-\pi)\left(\theta_{\mathrm{H}}-\theta_{\mathrm{L}}\right)\right)}{\partial d}=1
$$

should hold, which is the analogue of Eq. (9). Now, for $\hat{p}_{1}=\bar{p}_{1}$, the $\theta_{\mathrm{L}}$-seller's condition of indifference between penetrating in and staying out simplifies to $U_{\mathrm{S}_{\mathrm{L}}}^{\mathrm{Im}}=\alpha\left(\theta_{\mathrm{H}}-\theta_{\mathrm{L}}\right)-d\left(\bar{x}_{\mathrm{L}}\right)=0$. By strict concavity of the function $\phi($.$) , if the$ right-hand side of Eq. (15) evaluated at $\hat{p}_{1}=\bar{p}_{1}$ is greater than one, that is, if

$$
\frac{\partial \phi\left(\alpha\left(\theta_{\mathrm{H}}-\theta_{\mathrm{L}}\right)\right)}{\partial d}>1
$$

then $\hat{p}_{1}>\bar{p}_{1}$, i.e., as explained in Section 3, the maximal screening price is preventing the buyer from setting $\hat{p}_{1}$ optimally. Then the buyer has to offer $\hat{p}_{1}=\bar{p}_{1}$ 
and induce a suboptimal effort. The following proposition summarizes the discussion above and presents the conditions under which the buyer's motive of efficiently screening out $\theta_{\mathrm{L}}$-sellers is in conflict with her motive of investing in the innate ability of her trading partner, in the case of proportional solutions.

Proposition 4. Under proportional solutions, in any PBE satisfying the Intuitive Criterion $\hat{y}_{i}=y_{i}^{*}$ for $i=L, H$ and $\hat{z}=z^{*}$.

If $f\left(y_{L}(\hat{z}), \hat{z}\right) \leqslant \pi\left(\theta_{H}-\theta_{L}\right)$, in any PBE the buyer terminates the relationship at the end of period one whenever $\mu=0$. Then, since in any screening PBE the first-period price is below cost, $\theta_{L}$-sellers cannot use a penetration strategy to upset a screening $P B E$ with positive effort.

If $f\left(y_{L}(\hat{z}), \hat{z}\right) \leqslant \pi\left(\theta_{H}-\theta_{L}\right)$, in any PBE the buyer will continue through the second period with the same seller even if $\mu=0$, given the investment pair $\left.\left(y_{L}(\hat{z}), \hat{z}\right)\right)$. If, in addition, Eq. (16) holds, the potential penetration strategy of $\theta_{L}$-sellers upsets the optimal-effort screening PBE and leads the buyer to set $\hat{p}_{1}=\bar{p}_{1}$ and induce a suboptimal effort. The buyer's expected utility $\underline{U}_{B}$ from inducing a screening PBE with suboptimal effort $\hat{x}_{H}$ is lower than her expected utility $\underline{U}_{B}$ under a zero-effort screening PBE if $\hat{x}_{H}<\alpha\left(\theta_{H}-\theta_{L}\right)$. Then the buyer will choose to induce a zero-effort screening PBE.

The results concerning the PBE investment strategies follow directly from the corresponding first-order conditions. The rest of Proposition 4 presents the conditions under which the potential penetration strategy of $\theta_{\mathrm{L}}$-sellers brings an upper bound $\bar{p}_{1}$ on first-period prices and prevents the buyer from increasing $\hat{p}_{1}$ to induce the efficient effort level. This happens if the investment technology is sufficiently productive so that $f\left(y_{\mathrm{L}}(z), z\right)>\pi\left(\theta_{\mathrm{H}}-\theta_{\mathrm{L}}\right)$ and Eq. (16) holds. Then the buyer has two options: inducing a screening PBE with suboptimal effort or a screening PBE with zero effort. Comparing the expected utilities $\underline{U}_{\mathrm{B}}$ and $\hat{U}_{\mathrm{B}}$ in Eq. (14) where $\hat{p}_{1}=\bar{p}_{1}$, she will choose the zero-effort screening PBE if the maximum effort $\hat{x}_{\mathrm{H}}$ that she can induce (by offering the maximal screening price $\bar{p}_{1}$ ) falls short of a critical amount given by $\alpha\left(\theta_{\mathrm{H}}-\theta_{\mathrm{L}}\right)$. In other words, the quality improvement $\hat{x}_{\mathrm{H}}$ that the buyer gets is not worth the surplus $\alpha\left(\theta_{\mathrm{H}}-\theta_{\mathrm{L}}\right)$ that she has to leave to the $\theta_{\mathrm{H}}$-seller.

Proposition 4 also suggests alternative policies that may be used to eliminate the conflict between efficient screening and investment incentives. A necessary condition for this conflict to be effective is $f\left(y_{\mathrm{L}}(z), z\right)>\pi\left(\theta_{\mathrm{H}}-\theta_{\mathrm{L}}\right)$ which is the analogue of Eq. (3) under proportional solutions. It states that when the buyer invests $\hat{z}$ and a $\theta_{\mathrm{L}}$-seller penetrates into the relationship to supplement $\hat{z}$ by his own best reply $y_{\mathrm{L}}(\hat{z})$, then the buyer will find it beneficial to continue with the $\theta_{\mathrm{L}}$-seller. Thus, the buyer can avoid the penetration of $\theta_{\mathrm{L}}$-sellers if she can commit herself to an investment strategy $\underline{z}$ sufficiently below $\hat{z}$ so that $f\left(y_{\mathrm{L}}(\underline{z}), \underline{z}\right) \leqslant \pi\left(\theta_{\mathrm{H}}-\right.$ $\left.\theta_{\mathrm{L}}\right)$. Then the $\theta_{\mathrm{L}}$-sellers would not consider penetrating into the relationship because the first-period price is below cost $\left(\hat{p}_{1}<c\right)$. As another possible remedy, the buyer may consider modifying the investment technology to decrease its 
productivity. As $f(y, z)$ is uniformly lower (or better still, if the productivity of the $\theta_{\mathrm{L}}$-seller's investment could be decreased without affecting the productivity of a $\theta_{\mathrm{H}}$-seller's investment), the maximal screening price $\bar{p}_{1}$ is higher and the potential conflict between investment and efficient screening vanishes. The buyer will avoid the potential penetration strategy of $\theta_{\mathrm{L}}$-sellers if under the new, modified investment technology $f\left(y_{\mathrm{L}}(\hat{z}), \hat{z}\right) \leqslant \pi\left(\theta_{\mathrm{H}}-\theta_{\mathrm{L}}\right)$. Note that this condition holds if $f(.,)=$.0 , in the rather extreme case of zero productivity or absence of an investment technology. In this case the buyer will never choose continuation with a $\theta_{\mathrm{L}}$-seller because the expected innate quality of an outside seller, $\pi \theta_{\mathrm{H}}+(1-$ $\pi) \theta_{\mathrm{L}}$, exceeds $\theta_{\mathrm{L}}$.

\section{Conclusion}

We have studied a two-period buyer-seller relationship where noncontractible quality is affected by privately known innate qualities, which can be improved through bilateral investments. There are two potential types of equilibria, screening and nonscreening. Both display an increasing pattern of prices. The paper identifies a conflict between the buyer's incentives to invest and motive to perform efficient screening. When efficient screening stipulates inducing effort on the incumbent seller to generate a temporary improvement in quality, the buyer has to offer a higher first-period price. But this high price may no longer serve the screening purpose because, given the anticipated investment incentives of the buyer, a low innate quality seller may find it beneficial to penetrate into the relationship, invest at his best-reply level and lock the buyer for the entire planning horizon. This is the potential conflict that upsets the screening equilibrium. To avoid this possibility, the buyer has to offer a lower first-period price and induce an inefficient equilibrium, given the investment technology in place. The alternative is to reduce the productivity of the investment technology so that noncooperatively decided investment strategies are below a threshold level and sellers of low innate quality who foresee that the buyer will terminate the relationship at the end of the first contract are screened out at the outset. Thus, the paper identifies a new source of inefficiency in relationships governed by incomplete contracts, where information is asymmetric and the parties make relationship-specific investments.

\section{Appendix A}

\section{Proof of Proposition 1}

Suppose that conditions (3), (4), (5) and (6) hold and consider a nonscreening PBE. Given the postulated beliefs of the buyer at the contract renewal stage, the $\theta_{\mathrm{H}}$-seller's equilibrium quality and investment must satisfy $q_{\mathrm{H}}^{*} \geqslant \bar{q}$ and $y_{\mathrm{H}}^{*} \geqslant \bar{y}$ 
while the $\theta_{\mathrm{L}}$-seller provides either $q_{\mathrm{L}}^{*}<\bar{q}$ or invests $y_{\mathrm{L}}^{*}<\bar{y}$ (or both). In the PBE constructed below, the $\theta_{\mathrm{L}}$-seller's optimum effort strategy is $x_{\mathrm{L}}^{*}=0$ and his equilibrium payoff can be expressed as follows:

$$
U_{\mathrm{S}_{\mathrm{L}}}=p_{1}-c-y_{\mathrm{L}}^{*}+p_{2}\left(0, y_{\mathrm{L}}^{*}, z^{*}\right)-c \geqslant 0 .
$$

Let $\bar{x}_{\mathrm{L}}$ be the maximum effort that the $\theta_{\mathrm{L}}$-seller may exert to imitate the $\theta_{\mathrm{H}}$-seller's quality and investment strategy, for given posterior beliefs $\mu=1$. The imitation strategy yields $U_{\mathrm{S}_{\mathrm{L}}}^{\mathrm{Im}}=p_{1}-c-y_{\mathrm{H}}^{*}-d\left(\bar{x}_{\mathrm{L}}\right)+p_{2}\left(1, y_{\mathrm{H}}^{*}, z^{*}\right)-c$. To have a separation of types, the imitation strategy of the $\theta_{\mathrm{L}}$-seller should not yield a surplus beyond the payoff he obtains through his equilibrium strategies. The relevant indifference condition of the $\theta_{\mathrm{L}}$-seller is $U_{\mathrm{S}_{\mathrm{L}}}^{\mathrm{Im}}=U_{\mathrm{S}_{\mathrm{L}}}$, that is,

$$
d\left(\bar{x}_{\mathrm{L}}\right)=y_{\mathrm{L}}^{*}-p_{2}\left(0, y_{\mathrm{L}}^{*}, z^{*}\right)-y_{\mathrm{H}}^{*}+p_{2}\left(1, y_{\mathrm{H}}^{*}, z^{*}\right)
$$

which yields the expression for $\bar{x}_{\mathrm{L}}$ given in the proposition. Since effort is costly, the $\theta_{\mathrm{H}}$-seller will obviously choose the minimum effort $x_{\mathrm{H}}^{*}=\max \left\{0, \bar{x}_{\mathrm{L}}-\left(\theta_{\mathrm{H}}-\right.\right.$ $\left.\left.\theta_{\mathrm{L}}\right)\right\}$ that convincingly signals his type. If the threshold level of investment in the buyer's beliefs satisfies $y_{\mathrm{L}}^{*} \leqslant \bar{y} \leqslant y_{\mathrm{H}}^{*}$, then the strategies above are sequentially rational and beliefs are consistent. Moreover, the postulated belief system satisfies the Intuitive Criterion. ${ }^{27}$ To obtain the optimal nonscreening contract $\left\{p_{1}^{*}\right\}$, we write the $\theta_{\mathrm{H}}$-seller's equilibrium payoff as

$$
U \mathrm{~S}_{\mathrm{H}}^{*}=p_{1}-c-d\left(x_{\mathrm{H}}^{*}\right)-y_{\mathrm{H}}^{*}+\left[p_{2}\left(1, y_{\mathrm{H}}^{*}, z^{*}\right)-c\right]
$$

which is nonnegative because $x_{\mathrm{H}}^{*} \leqslant x_{\mathrm{L}}^{*}$ and $U_{\mathrm{S}_{\mathrm{L}}}^{*}=0$. Clearly, $p_{1}$ should be chosen as low as possible, to bind the participation constraint of the $\theta_{\mathrm{L}}$-seller. Thus, $p_{1}^{*}=2 c+y_{\mathrm{L}}^{*}-p_{2}\left(0, y_{\mathrm{L}}^{*}, z^{*}\right)$, and by Eq. (5), $p_{1}^{*}<c$.

In a nonscreening PBE where Eq. (3) does not hold, the buyer terminates the relationship if $\mu=0$. The $\theta_{\mathrm{L}}$-seller's corresponding strategies are $y_{\mathrm{L}}^{*}=0$ and $x_{L}^{*}=0$, which yields $U_{\mathrm{S}_{\mathrm{L}}}=p_{1}-c$. The $\theta_{\mathrm{H}}$-seller determines his equilibrium effort according to $x_{\mathrm{H}}^{*}=\left\{0, \bar{x}_{\mathrm{L}}-\left(\theta_{\mathrm{H}}-\theta_{\mathrm{L}}\right)\right\}$, where $\bar{x}_{\mathrm{L}}=\phi\left(p_{2}\left(1, y_{\mathrm{H}}^{*}, z^{*}\right)-c-y_{\mathrm{H}}^{*}\right)$ is

\footnotetext{
${ }^{27}$ To see this, note that $q_{\mathrm{H}}^{*}$ is the minimum quality that cannot beneficially be imitated by the $\theta_{\mathrm{L}}$-seller, and also that if $\bar{q}<q_{\mathrm{H}}^{*}$, any such $\bar{q}$ can also beneficially be mimicked by the $\theta_{\mathrm{L}}$-seller. Clearly, any belief system which postulates a quality threshold $\bar{q}$ that exceeds $q^{*}$ fails the Intuitive Criterion because the quality $q^{*}$ cannot be mimicked by the $\theta_{\mathrm{L}}$-seller, hence is a convincing signal that $\theta=\theta_{\mathrm{H}}$. As for the threshold investment $\bar{y}$, given $\bar{q}=q^{*}$, setting $y>y_{\mathrm{H}}^{*}$ and $\mu=1$ for $y \geqslant \bar{y}$ cannot be part of a PBE belief system satisfying the Intuitive Criterion. Suppose it is, and consider the investment strategies $z^{*}(\bar{y})$ and $\bar{y}$ of the buyer and the $\theta_{\mathrm{H}}$-seller. Now $\bar{y}$ is not a best reply to $z^{*}(\bar{y})$. According to these beliefs the $\theta_{\mathrm{H}}$-seller must invest $\bar{y}$, even more than $y_{\mathrm{H}}^{*}$, in order to signal his type. However, if he deviates to the best reply $y_{\mathrm{H}}^{*}\left(z^{*}(\bar{y})\right)$ and keeps providing the quality $q^{*} \geqslant \bar{q}$, the buyer must still believe that she faces a $\theta_{\mathrm{H}}$-seller. This deviation is 'bad' for the $\theta_{\mathrm{L}}$-seller, and not 'bad' for the $\theta_{\mathrm{H}}$-seller. It follows that $\bar{y}$ should not exceed $y_{\mathrm{H}}^{*}$. On the other hand, note that the $\theta_{\mathrm{L}}$-seller's investment $y_{\mathrm{L}}^{*}$ is irrelevant for revising beliefs in the presence of the convincing quality signal $q \geqslant \bar{q}$.
} 
determined as above, through the $\theta_{\mathrm{L}}$-seller's indifference between imitating $\theta_{\mathrm{H}^{-}}$ seller and playing his own strategy. Since $\bar{x}_{\mathrm{L}}$ is independent of $p_{1}$, the buyer should set $p_{1}$ as low as possible, therefore in a nonscreening PBE where the buyer sets $b=1$ only if $\theta=\theta_{\mathrm{H}}, p_{1}^{*}=c$. Decreasing $p_{1}$ by $\varepsilon$ arbitrarily small would then screen out the $\theta_{\mathrm{L}}$-seller without significantly affecting equilibrium effort, and generate an improvement of $(1-\pi)\left(\theta_{\mathrm{H}}-\theta_{\mathrm{L}}\right)$ in expected first-period quality. Therefore nonscreening contracts that induce continuation with only the $\theta_{\mathrm{H}}$-seller are dominated.

Imposing the Intuitive Criterion on the buyer's beliefs eliminates all potential pooling equilibria (where quality and investment strategies are not informative). This follows from the discussion above and the innate advantage of the $\theta_{\mathrm{H}}$-seller in providing quality. Finally, since any nonscreening PBE must be of the separating type, $p_{1}^{*}<c$. A price $p_{1}>c$ cannot generate a screening PBE because it offers a net positive surplus to $\theta_{\mathrm{L}}$-sellers who would accept the contract, choose zero effort and investment to leave the relationship at the end of period one.

\section{Proof of Proposition 2}

Since $\mu=1$ in a screening $\mathrm{PBE}, \hat{b}=1$ is clearly the unique optimum continuation strategy of the buyer at the contract renewal stage. By the arguments in the proof of Proposition 1, setting quality and investment thresholds as $\bar{q}=\hat{q}_{\mathrm{H}}$ and $\bar{y} \leqslant \hat{y}_{\mathrm{H}}$ constitutes a belief system that satisfies the Intuitive Criterion and is consistent with the following equilibrium strategies: $\hat{y}_{\mathrm{H}}$ satisfies Eq. (4), and $\hat{q}_{\mathrm{H}}=\theta_{\mathrm{H}}+\hat{x}_{\mathrm{H}}$ where $\hat{x}_{\mathrm{H}}=\max \left\{0, \bar{x}_{\mathrm{L}}-\left(\theta_{\mathrm{H}}-\theta_{\mathrm{L}}\right)\right\}$ and $\hat{x}_{\mathrm{L}}$ is defined as in the proposition. Since $p_{2}\left(1, \hat{y}_{\mathrm{H}}, \hat{z}\right)$ and $\hat{y}_{\mathrm{H}}$ are unique, $\hat{x}_{\mathrm{L}}$ is unique, and so is $\hat{x}_{\mathrm{H}}$. It is always possible to induce a zero-effort equilibrium $\left(\hat{x}_{\mathrm{H}}=0\right)$, by choosing the price $\hat{p}_{1}$ that binds the $\theta_{\mathrm{H}}$-seller's participation constraint: $\hat{p}_{1}=2 c+\hat{y}_{\mathrm{H}}-p_{2}\left(1, \hat{y}_{\mathrm{H}}, \hat{z}\right)$. In a zero-effort equilibrium, the buyer can thus extract the whole corresponding surplus and guarantee herself the utility level $\underline{U}_{\mathrm{B}}$.

\section{Proof of Lemma 1}

Recall that both seller types have the same outside option and in any nonscreening $\mathrm{PBE} U_{\mathrm{S}_{\mathrm{H}}}>U_{\mathrm{S}_{\mathrm{L}}}=0$, whereas in a screening PBE with zero effort, $U_{\mathrm{S}_{\mathrm{H}}}=U_{\mathrm{S}_{\mathrm{L}}}=0$. The claim $p_{1}^{*}>p_{1}$ follows from the fact that $\hat{p}_{1}$ and $p_{1}^{*}$ bind the participation constraints of, respectively, the $\theta_{\mathrm{H}^{-}}$and the $\theta_{\mathrm{L}}$-seller. To show the second claim, write the price differential $\bar{p}_{1}-p_{1}^{*}$ as

$$
\begin{aligned}
\bar{p}_{1}-p_{1}^{*} & =p_{2}\left(0, y_{\mathrm{L}}^{*}, z^{*}\right)-y_{\mathrm{L}}^{*}-\left[p_{2}\left(0, y_{\mathrm{L}}(\hat{z}), \hat{z}\right)-y_{\mathrm{L}}(\hat{z})\right] \\
& =\max _{y}\left\{p_{2}\left(0, y, z^{*}\right)-y\right\}-\max _{y}\left\{p_{2}(0, y, \hat{z})-y\right\}
\end{aligned}
$$

This expression is negative, hence $p_{1}^{*} \geqslant \bar{p}_{1}$, if $z^{*} \leqslant \hat{z}$. 


\section{References}

Acemoglu, D., Pischke, J.-S., 1996. Why do firms train? Theory and evidence, Working Paper No. 5605, NBER.

Aghion, P., Dewatripont, M., Rey, P., 1994. Renegotiation design with unverifiable information. Econometrica 62, 257-282.

Bac, M., 1993. Opportunism and the dynamics of incomplete contracts. International Economic Review 33, 663-683.

Bac, M., 1997. Bilateral relationships governed by incomplete contracts. Journal of Institutional and Theoretical Economics 153, 319-333.

Bac, M., forthcoming. On-the-job specific training and efficient screening, Journal of Labor Economics.

Crawford, V.P., 1988. Long-term relationships governed by short-term contracts. American Economic Review 78, 485-499.

Chung, T.Y., 1991. Incomplete contracts, specific investments and risk sharing. Review of Economic Studies 58, 1031-1042.

Edlin, A., Reichelstein, S., 1993. Holdups, standard breach remedies, and optimal investment, Working Paper, UC Berkeley.

Farrell, J., Shapiro, M., 1989. Optimal contracts with lock-in. American Economic Review 79, 51-68.

Freixas, X., Guesnerie, R., Tirole, J., 1985. Planning under incomplete information. Review of Economic Studies 52, 171-191.

Fudenberg, B., Holmstrom, B., Milgrom, P., 1990. Short-term contracts and long-term agency relationships. Journal of Economic Theory 52, 194-206.

Harrington, J.E., 1993. The impact of reelection pressures on the fulfillment of campaign promises. Games and Economic Behavior 5, 71-97.

Hart, O., Moore, J., 1988. Incomplete contracts and renegotiation. Econometrica 56, 755-785.

Holmstrom, B., 1982. Managerial incentive problems-A dynamic perspective. In: Walross, B. (Ed.), Essays in Economics and Management in Honor of Lars Wahlbeck. Swedish School of Economics, Helsinki.

Kalai, E., 1977. Proportional solutions to bargaining situations: Intertemporal utility comparisons. Econometrica 50, 97-109.

Laffont, J.J., Tirole, J., 1988. The dynamics of incentive contracts. Econometrica 56, 457-478.

Tirole, J., 1986. Procurement and renegotiation. Journal of Political Economy 94, 235-259.

Williamson, O., 1975. Markets and Hierarchies: Analysis of Antitrust Implications. The Free Press, New York.

Williamson, O., 1985. The Economic Institutions of Capitalism. The Free Press, New York. 